\title{
ESTUDO DE PATOLOGIAS EM ESTRADAS NÃO PAVIMENTADAS DA MALHA RODOVIÁRIA PIAUIENSE
}

\author{
ALMEIDA, FRANCISCO \\ Assistente de Controle Externo \\ Tribunal de Contas do Estado do Piauí \\ Piauí; Brasil \\ rogeanio.almeida@tce.pi.gov.br
}

\author{
SANTANA, CLAUDENY \\ Assistente de Controle Externo \\ Tribunal de Contas do Estado do Piauí \\ Piauí; Brasil \\ cl_deny@yahoo.com.br
}

\author{
VILARINHO, EDUARDO \\ Auditor de Controle Externo \\ Tribunal de Contas do Estado do Piauí \\ Piauí; Brasil \\ envilarinho@hotmail.com \\ SILVA, LEONARDO \\ Graduando em Engenharia Civil \\ Centro Universitário Uninovafapi \\ Piauí; Brasil \\ leonardsousa.silva@gmail.com
}

\section{RESUMO}

O presente trabalho trata de estudo das principais patologias em estradas não pavimentadas no estado do Piauí. Partindo de atividades desenvolvidas por equipe técnica do TCE/PI, através de inspeções em trechos de vias em revestimento primário, foram identificados os defeitos típicos de estradas vicinais da malha rodoviária local, a fim de averiguar as condições dessas vias e avaliar as causas dos recorrentes degastes da plataforma. Assim, de posse do mapeamento das patologias existentes nas vias, constatou-se que o seu surgimento está diretamente relacionado à forma de execução dos serviços de melhoramento da capacidade de suporte e serventia ao tráfego, muitas vezes negligenciada pelos responsáveis pela contratação das obras, que dispensam a aplicação de técnicas construtivas adequadas. Soma-se a isso o fato de que, para a realidade do estado do Piauí, há escassez de estudos capazes de difundir técnicas de pavimentação de baixo custo, principalmente com emprego de novos materiais.

Palavras-chave: vias não pavimentadas, estradas vicinais, patologias.

\section{ABSTRACT}

The present work deals with the study of the main pathologies in unpaved roads in the state of Piauí. Based on the activities carried out by the TCE / PI technical team, through inspections of stretches of primary-lined roads, the typical defects of local roads of the local road network were identified in order to ascertain the conditions of these roads and to evaluate the causes of the applicants. platform breakdowns. Thus, having mapped the existing pathologies in the roads, it was found that their emergence is directly related to the execution of services to improve the support capacity and service to traffic, often overlooked by those responsible for contracting the works, which do not require proper construction techniques. Add to this the fact that, for the reality of the state of Piauí, there is a scarcity of studies capable of spreading low cost paving techniques, especially with the use of new materials.

Keywords: unpaved roads, back roads, pathologies. 


\section{INTRODUÇÃO}

O desenvolvimento socioeconômico de um país está diretamente relacionado à dimensão da infraestrutura da qual dispõe, uma vez que esta responde pelo escoamento de toda a atividade produtiva e permite o fluxo das riquezas do país. Assim, defende-se que a importância do setor de transportes não se limita a interligar zonas de determinadas atividades, mas contribuir para o processo de produção, circulação e distribuição de mercadorias, refletindo ainda na melhoria da qualidade de vida da população; corroborando com a ideia acima, Antas et al. (2010) afirma que o setor de transportes absorve grande parcela dos investimentos do país, com a justificativa dada por seu papel desencadeador de produção.

Segundo Oda (1995), as estradas não pavimentadas resultam, geralmente, da evolução de passagens precárias que, com o tempo e o aumento do volume de tráfego, passam a necessitar de melhorias nas condições de rolamento, apresentando um traçado delimitado naturalmente pelo terreno e evitando, por meio de desvios, declividades pronunciadas e obstáculos locais. Dessa forma, Almeida (2015) ressalta que o caráter simplório desse tipo de via não garante vida útil prolongada, exigindo, por esta razão, constantes atividades de manutenção.

As pesquisas mais recentes sobre a extensão rodoviária brasileira, feitas pela Confederação Nacional dos Transportes (CNT), mostram que a maior parcela da malha rodoviária é ocupada pelas estradas não pavimentadas, em torno de 79\%, e somente pequena parcela das rodovias são pavimentadas, cerca de $12 \%$ conforme a Figura 1. Mesmo diante dessa grande representatividade os investimentos em vias não pavimentadas ainda são consideravelmente tímidos.

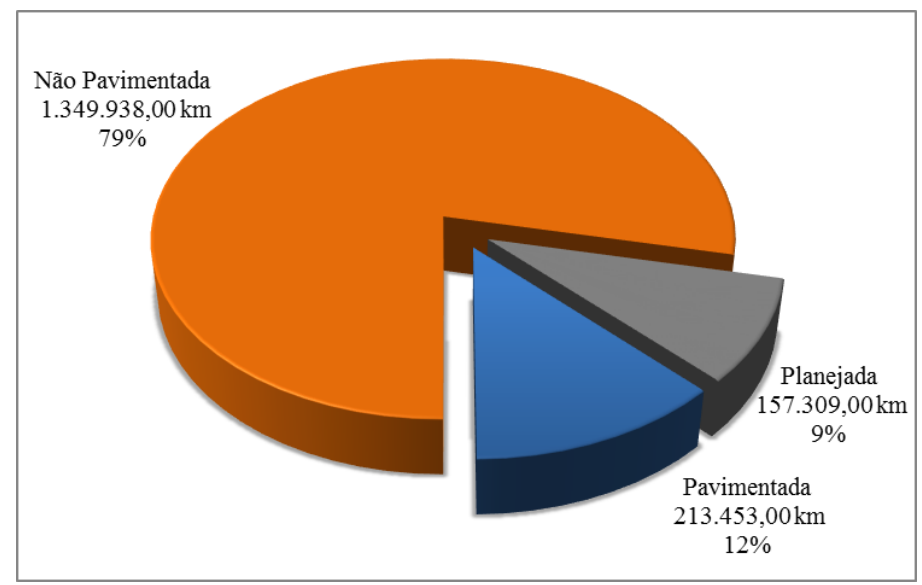

Figura 1: Malha Rodoviária do Brasil (2017)

No Piauí o cenário é bastante semelhante, de acordo com dados da CNT de 2017, o Estado do Piauí apresenta uma extensão total de rodovias de $62.088,30 \mathrm{~km}$. Assim, constatou-se que $81 \%$ da malha rodoviária piauiense é composta de rodovias não pavimentadas, como ilustrado na Figura 2.

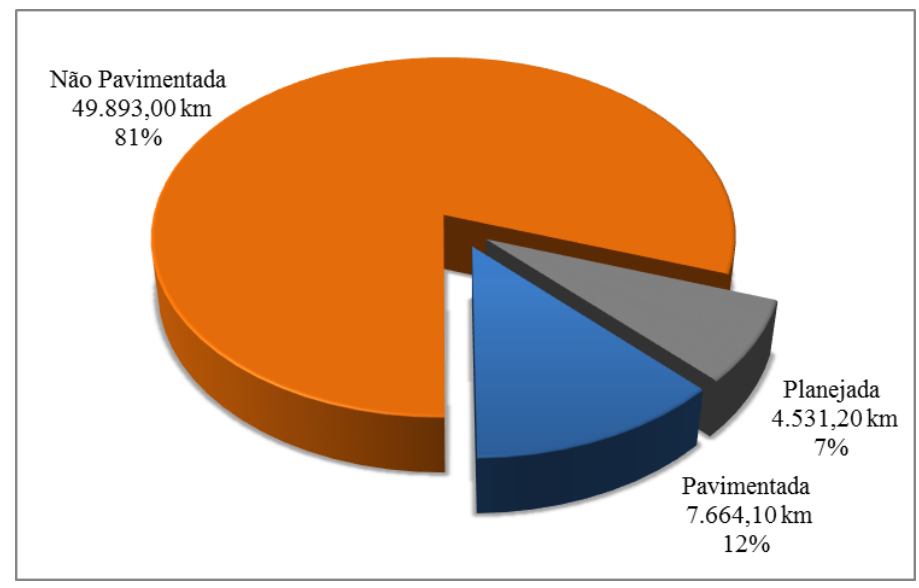

Figura 2: Malha Rodoviária do Estado do Piauí (2017) 
Considerando toda essa representatividade das estradas não pavimentadas em relação à extensão total de rodovias piauienses, procura-se ressaltar a necessidade de investimentos nessas vias, o que muitas vezes não é previsto pelos gestores de órgãos que realizam serviços em estradas vicinais. Assim, por conta do baixo investimento em restauração e manutenção, essas rodovias apresentam problemas e consequentemente afetam a qualidade de vida de quem por elas trafegam. Neste sentido, o presente trabalho tem por objetivo apresentar as principais manifestações patológicas constatadas a partir da análise da malha rodoviária não pavimentada do Estado do Piauí.

\section{METODOLOGIA}

No tocante à pesquisa documental, foi realizada uma investigação por meio de documentos cedidos pelo Tribunal de Contas do Estado do Piauí, a fim de verificar as principais irregularidades já apontadas na fiscalização de estradas não pavimentadas. Em relação à coleta de dados, foram consultadas ferramentas de controle de gastos de recursos públicos a fim de determinar os valores aplicados em obras rodoviárias pelos órgãos da Administração Estadual do Piauí, bem como os respectivos serviços contratados, cuja malha rodoviária inspecionada atingiu a ordem de 500 km de extensão.

Como forma de elaborar informações a partir dos dados coletados e para apontar causas dos fenômenos ocorridos, também foram consultadas outras fontes que fornecem dados que contribuem para o problema desta pesquisa, a exemplo da ANP e DNIT. Nesse sentido, a pesquisa se configura como experimental, pois as variáveis são relacionadas com o objeto de estudo, obtendo as causas e efeitos de determinada ação ou fenômeno.

\section{RESULTADOS E ANÁLISES}

Oliveira (2005) caracteriza os defeitos segundo: dimensões, tipo e severidade. As dimensões podem ser expressas segundo a extensão superficial (área, diâmetro, espessura); o tipo pode ser definido como as manifestações mais comuns, que Baesso e Gonçalves (2003) sintetizam para vias não pavimentadas em seção transversal imprópria, drenagem inadequada, corrugações, excesso de poeira, buracos, trilha de roda e perda de agregados; e a severidade é a intensidade com que o defeito atrapalha e afeta conforto e segurança dos veículos em trânsito, segundo Oliveira (2005).

Em adendo a tais definições, Oda (1995) agrupa os defeitos em função do solo predominante na estrada e de acordo com o período de manifestação do problema. Segundo a pesquisadora, em vias com leito constituído de solo arenoso, são recorrentes ondulação, materiais soltos, buracos (em trechos planos) e erosão (em trechos com rampas acentuadas). Nas rodovias com solo argiloso, os defeitos mais frequentes em épocas de chuvas são os atoleiros (em trechos planos) e pista escorregadia (ausência de aderência pneu-pista); em períodos de seca, os principais defeitos são a poeira e a segregação de agregados.

\subsection{Panelas}

Eaton, Gerard e Dattilo (1987) apud ODA (1995) descrevem buracos, identificados também por panelas, como pequenas depressões em forma de bacia na superfície da estrada, normalmente menores que $100 \mathrm{~cm}$ de diâmetro, tendo seu crescimento acelerado pela umidade no interior do defeito. Os buracos são produzidos quando o tráfego desgasta pequena parte da superfície da estrada, ocorrendo a contínua expulsão de partículas sólidas do leito carroçável.

De acordo com Santos et al. (1988), o aparecimento de buracos é uma consequência imediata de uma plataforma com drenagem deficiente que, provavelmente, não disponha de abaulamento transversal. Baesso e Gonçalves (2003) enumeram, além da causa supracitada, outras duas razões para a formação de buracos na superfície de rolamento das estradas: a inexistência de camada de revestimento primário ou deficiências quanto à composição de sua mistura e a ausência de partículas aglutinantes na composição dos materiais da camada.

Tabela 1 - Níveis de severidades dos buracos (ODA, 1995)

\begin{tabular}{c|l}
\hline Nível de Severidade & \multicolumn{1}{c}{ Característica } \\
\hline Baixa & $\begin{array}{l}\text { buracos com profundidade menor que } 2,5 \mathrm{~cm} \text { e/ou } \\
\text { diâmetro menor que } 30 \mathrm{~cm}\end{array}$ \\
\hline Média & $\begin{array}{l}\text { buracos com profundidade entre } 2,5 \text { e } 5,0 \mathrm{~cm} \text { e/ou } \\
\text { diâmetro entre } 30 \text { e } 60 \mathrm{~cm}\end{array}$ \\
\hline Alta & $\begin{array}{l}\text { buracos com profundidades maiores que } 7,5 \mathrm{~cm} \\
\text { e/ou diâmetro maior que } 60 \mathrm{~cm}\end{array}$ \\
\hline
\end{tabular}


Dependendo do nível de severidade da ocorrência dos buracos na faixa trafegável de uma estrada rural, as estratégias de intervenção podem envolver desde técnicas simples a intervenções mais complexas e onerosas. Santos et al. (1988), por exemplo, recomenda a reconstituição da drenagem das águas da plataforma, na maioria dos casos a reconstrução do abaulamento transversal, das valetas e das sangras, seguido do tapamento dos buracos.

Baesso e Gonçalves (2003) sugerem intervenções simples, a exemplo da operação de tapa-buraco e a execução de uma leve regularização por meio da motoniveladora, que realizará uma espécie de nivelamento da superfície de rolamento, sem descuidar quanto à configuração do abaulamento ideal para a pista, situando-se em torno de $4 \%$.

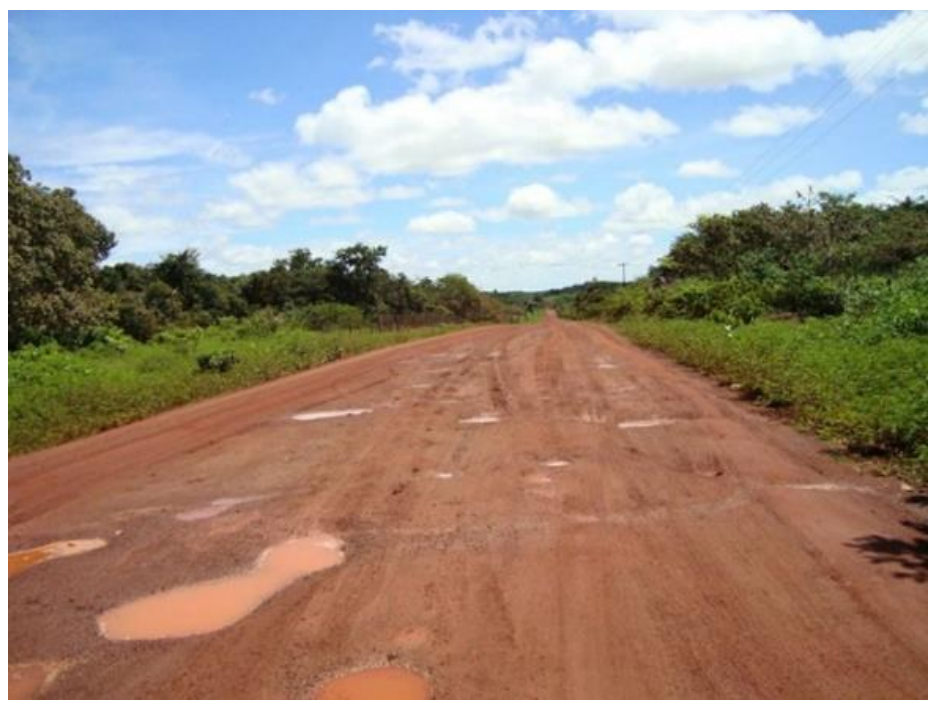

Figura 3: Formação de buracos na pista de rolamento de uma estrada rural

Em contrapartida, intervenções mais complexas também são indicadas por Baesso e Gonçalves (2003) em trechos com elevada taxa de buracos (Figura 3) de uma via ou segmento desta. Sugere-se que haja a recomposição do trecho defeituoso, executando o corte da plataforma por meio de uma motoniveladora, a uma profundidade não menor que aquela das depressões, devendo ser realizada, posteriormente, a reconformação da plataforma utilizando o material existente na via. Finalmente, executam-se o espalhamento do material que foi cortado, concomitante com o acabamento final da superfície de rolamento.

\subsection{Trilha de Roda}

Um afundamento de trilhas de rodas é uma depressão na superfície do caminho da roda (pneu). O afundamento é causado por uma deformação permanente em qualquer camada da estrada ou do subleito, resultado de cargas repetidas de tráfego, especialmente quando a capacidade de suporte é baixa e em períodos de chuva (ODA, 1995). Também surgem quando a drenagem da plataforma é deficiente.

Quanto à ocorrência, Ferreira (2004) destaca que os afundamentos das trilhas de roda ocorrem, notadamente, em estradas com solo argiloso, podendo, em razão da falta de manutenção, permitir o crescimento de vegetação no centro da pista de rolamento (Facão), que dificulta ainda mais a passagem dos veículos. Tratando dos níveis severidade, as considerações seguintes, fundamentadas em Oda (1995) e conjugadas à Tabela 2.

Tabela 2 - Níveis de severidades das trilhas de rodas conforme (ODA, 1995)

\begin{tabular}{c|c}
\hline Nível de Severidade & Característica \\
\hline Baixa & sulcos com profundidade menor que $2,5 \mathrm{~cm}$ \\
\hline Média & sulcos com profundidade entre 2,5 e $7,5 \mathrm{~cm}$ \\
\hline Alta & sulcos com profundidade maior que $7,5 \mathrm{~cm}$ \\
\hline
\end{tabular}

Como ilustração do problema na prática, a Figura 4 representa a manifestação das trilhas de roda em uma estrada rural no interior do Estado do Piauí. 


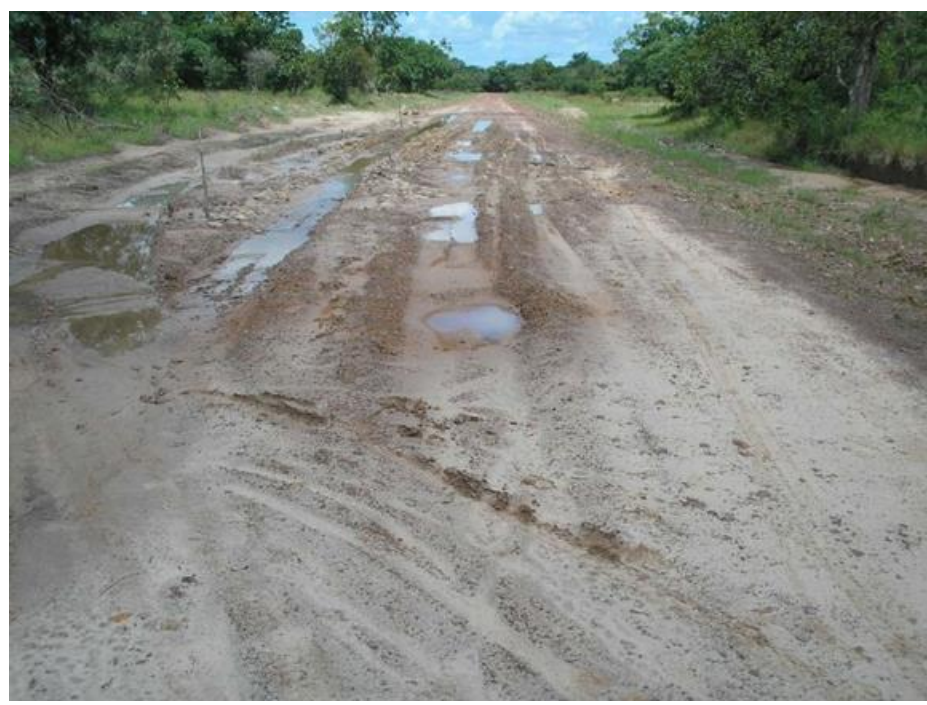

Figura 4: Afundamentos de trilhas de roda em uma estrada rural

Eaton e Beaucham (1992 apud SANTANA, 2006) consideram que uma via com baixa severidade quanto à formação das trilhas de roda deve ser apenas nivelada de modo que permita a recomposição do material no leito estradal. Para um nível médio de severidade é sugerido o simples nivelamento ou a adição de material para balanceamento da mistura, com espalhamento e compactação. Para o caso de alto nível de severidade ocasionado em consequência de um baixo suporte do material presente na via, a plataforma deverá ser cortada e executar adição de material granular, seguida da homogeneização e compactação.

Baesso e Gonçalves (2003) alertam que se as trilhas de roda não forem atacadas imediatamente após seu aparecimento, podem tornar a estrada intransitável. Para isso, sugerem soluções a depender do nível de severidade das trilhas de roda. Neste enfoque, têm-se: Severidade baixa, simples regularização da plataforma por meio da motoniveladora; Severidade média, regularização e reconformação da pista de rolamento, envolvendo a adição de materiais para balanceamento da mistura, seguida do espalhamento e, por fim, execução adequada dos serviços de compactação da plataforma; Severidade alta, serviços de drenagem (profunda ou superficial), recomposição da área afetada pelas trilhas substituindo os solos ou adicionando materiais com posterior revolvimento e aeração para compactação final e execução da camada de revestimento.

\subsection{Drenagem Inadequada}

Além de ser causa raiz para vários outros defeitos, a drenagem inadequada, ou em funcionamento deficiente, pode mudar as características de rolamento das estradas não pavimentadas, podendo alcançar, da mesma forma que a seção transversal inadequada, os três níveis de severidade outrora descritos, tal como ilustrado na Figura 5.
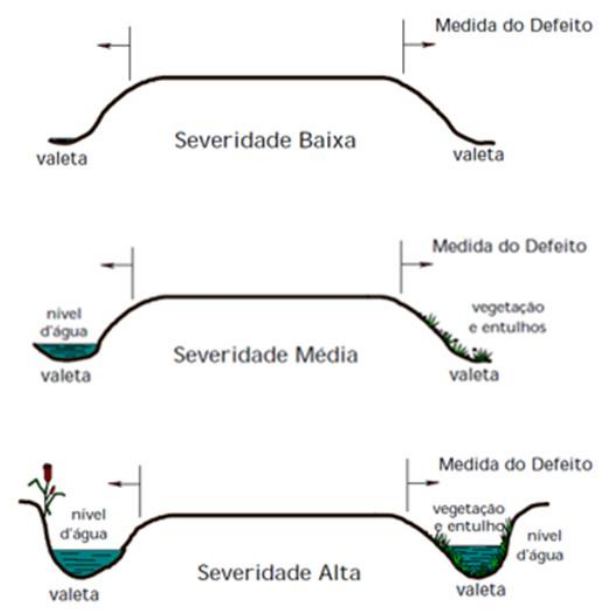

Figura 5: Níveis de severidades com drenagem inadequada (ODA, 1995) 
Baesso e Gonçalves (2003) caracterizam este defeito por permitir o acúmulo de água na plataforma, ocasionado pelo mau funcionamento dos dispositivos de drenagem superficial, inexistência de elementos de drenagem profunda, como também pela falta de manutenção das obras de arte correntes, no caso dos bueiros, meios-fios, sarjetas, valetas de proteção de corte e de aterros e descidas d'água, que se verificam, por vezes, cobertas de vegetação e/ou entulhos.

Dependendo do grau de deterioração do pavimento, a manutenção da drenagem deve ser realizada com a limpeza das valetas no máximo a cada dois anos, para uma baixa severidade deste defeito. $\mathrm{Na}$ média severidade, as valetas deverão ser reconformadas, construídas ou compactadas e os bueiros desobstruídos; já para um alto nível de severidade, deverá ser instalado dreno profundo, aumentado os bueiros, ou empregada a proteção com ou geotêxteis (EATON e BEAUCHAM, 1992) apud (SANTANA, 2006).

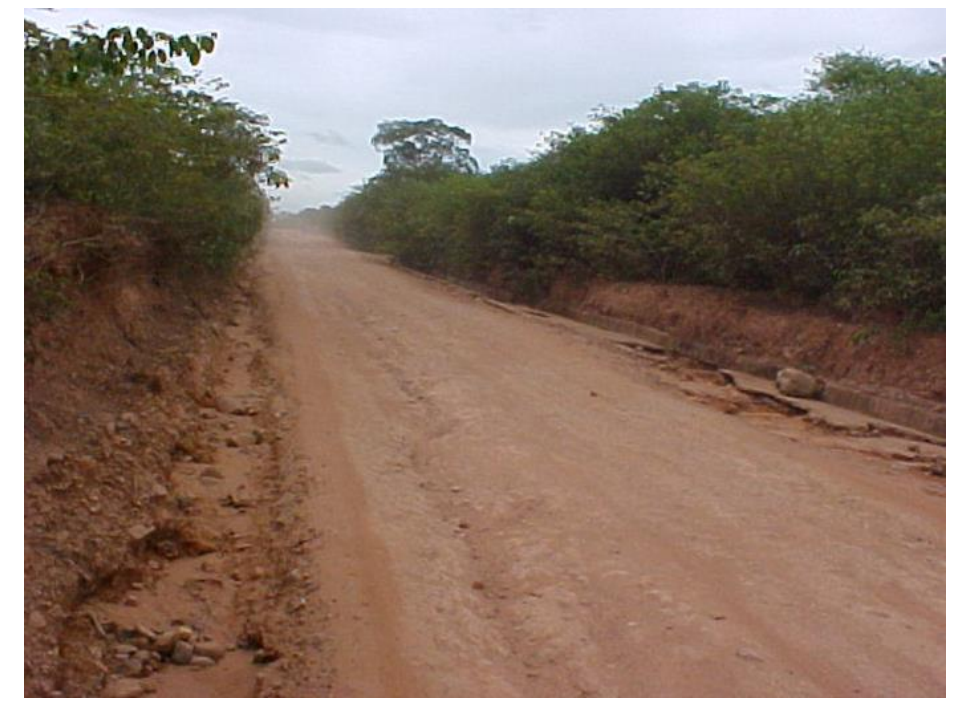

Figura 6: Estrada vicinal defeituosa por conta da drenagem inadequada

Qualquer que seja o problema relacionado a defeitos na drenagem da via, a correção do defeito deve sempre iniciar pela retirada da água acumulada nos dispositivos de drenagem (sarjeta, valeta, bueiros, etc.) por meios de sangras e valetas, de modo que haja condições de se intervir na plataforma da estrada, implementando, em seguida, a reconstituição da pista por meio de camadas de revestimento e reconstruindo os dispositivos de drenagem.

\subsection{Corrugações}

Baesso e Gonçalves (2003) abordam as corrugações como uma situação-problema caracterizada por deformações que surgem na pista de rolamento das estradas rurais, posicionadas em intervalos regulares, perpendicularmente ao sentido de fluxo do tráfego e oriundos de diversos fatores, quais sejam: ação contínua do tráfego, perda de agregados finos da superfície de rolamento, deficiências de suporte do material do subleito, abaulamento insuficiente e revestimentos de baixa qualidade aliado a períodos longos de seca.

Nunes (2003) trata as corrugações com outra terminologia: ondulações, afirmando que as regulares têm ocorrência em estradas planas formadas por solos arenosos, enquanto que as ondulações irregulares ocorrem em estradas formadas por solos argilosos que, ao secarem, se contraem formando o defeito.

Registre-se também que na região Nordeste do Brasil, este defeito é bastante identificado por "costela de vaca".

Eaton, Gerard e Dattilo (1987) e Fontenele (2001) classificam os níveis de severidade em função da profundidade da ondulação. Já Eaton e Beaucham (1992 apud SANTANA, 2006) adiciona ao critério de classificação a área tangida pelas ondulações, conforme Tabela 3 .

Tabela 3 - Níveis de severidade da ondulação (EATON et al; 1987)

\begin{tabular}{c|l}
\hline Nível de Severidade & \multicolumn{1}{c}{ Característica } \\
\hline Baixa & ondulações cujas profundidades são menores que 2,5 cm \\
\hline Média & ondulações cujas profundidades estejam entre 2,5 e 7,5 cm \\
\hline Alta & $\begin{array}{l}\text { ondulações cujas profundidades se acham maiores que 7,5 } \\
\mathrm{cm}\end{array}$ \\
\hline
\end{tabular}


Dessa forma, as corrugações ou ondulações, conforme ideia de Baesso e Gonçalves (2003), constituem-se de grave problema para a manutenção das estradas de terra, principalmente em épocas de seca, causando trepidação nos veículos e, consequentemente, desconforto aos usuários. A Figura 7 representa, na prática, a manifestação desse defeito

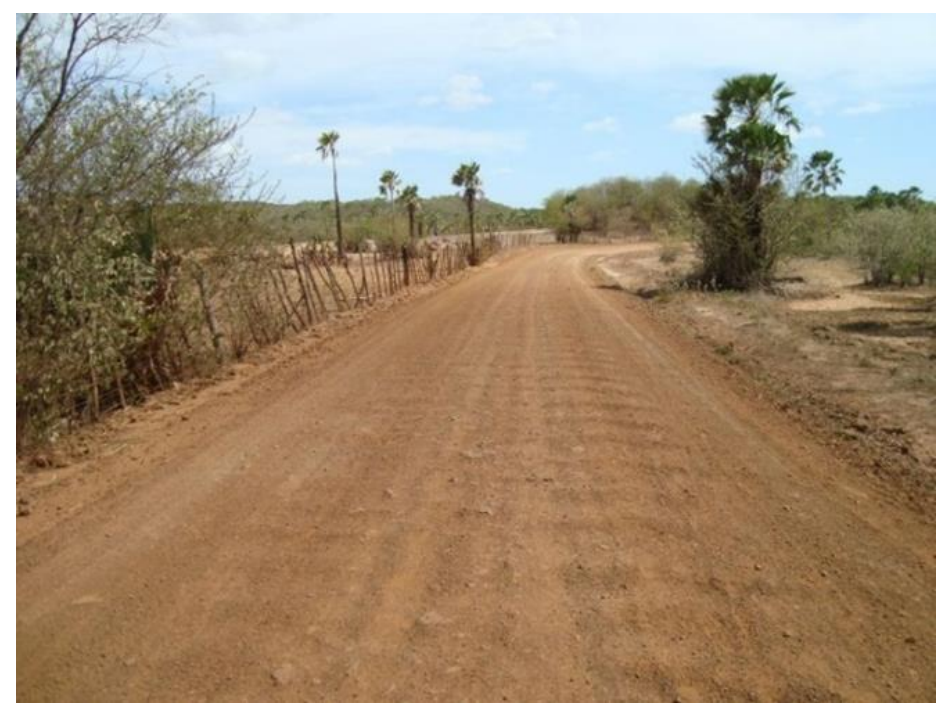

Figura 7: Estrada vicinal comprometida por corrugações

Como alternativa de solução, Baesso e Gonçalves (2003) aconselham que o revestimento da pista de rolamento seja executado com material cuja composição granulométrica seja adequadamente balanceada e em presença de fração plástica a fim de conferir poder de aglutinação, de modo a resistir à formação de corrugações; entretanto, ressalta-se que, teoricamente, qualquer tipo de superfície desenvolve leves níveis de corrugações sob a ação do tráfego e o ponto chave consiste na manutenção da mistura da camada de rolamento em proporções ideais.

\subsection{Atoleiros}

Almeida, R. (2006) define atoleiro como uma camada de lama onde não existe atrito entre o solo e os pneus do veículo, que patinam sem sair do lugar. Dependendo do tipo de solo, os atoleiros surgem por conta da baixa capacidade de suporte do subleito e, principalmente, devido à ausência ou deficiência do sistema de drenagem, que, conforme já abordado, contribui para surgimento de qualquer defeito em rodovias.

Verifica-se que os constantes serviços de patrolamento da pista de rolamento, denominadas raspagem, tendem a tornar a plataforma da rodovia encaixada no terreno, construindo, dessa forma, uma calha que dificulta o escoamento de água para as laterais , a qual possibilita o acúmulo de água na forma de "poças" (Figura 8), impedindo o tráfego dos veículos.

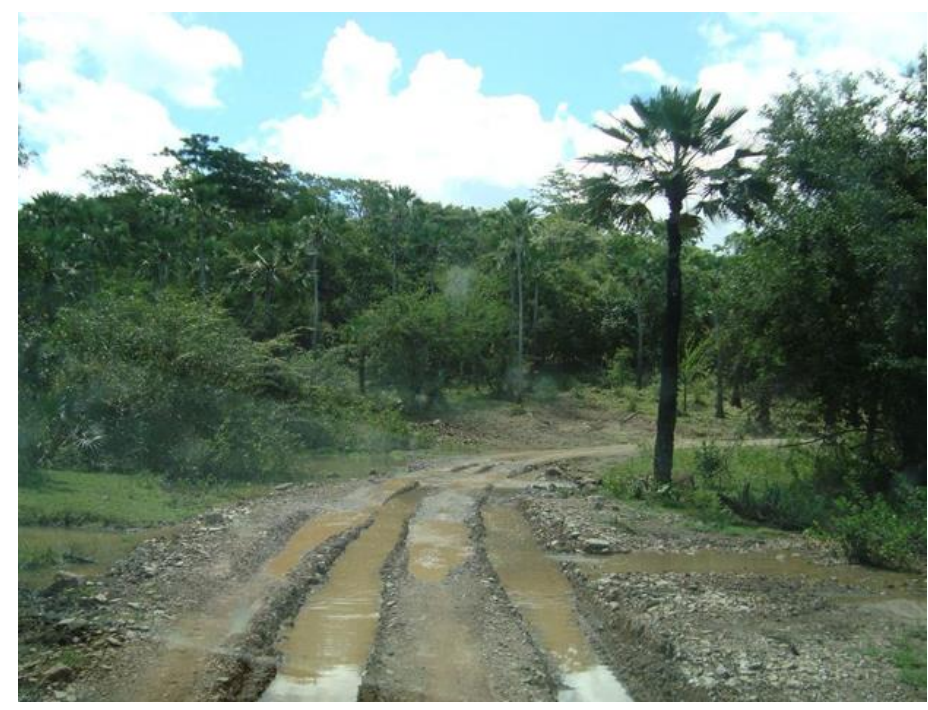

Figura 8: Estrada vicinal comprometida por atoleiro 
Santana (2006) apresenta outro fator que pode ocasionar a formação de atoleiros que são os casos onde a pista de rolamento se encontra com a declividade transversal invertida, situação que também impossibilita o escoamento da água para as laterais. Ressalva se faz ao fato de os atoleiros provocarem a interrupção da estrada em períodos chuvosos, pois as poças d'água se tornam constantes, deixando o solo saturado, reduzindo sua resistência e, por conseguinte, impossibilitando o tráfego dos veículos.

As técnicas de correção dos atoleiros se assemelham às dos buracos: retirada da água empoçada, conduzindo-as para os dispositivos de drenagem e reconstrução do revestimento primário, de preferência sobre uma camada com subleito reforçado.

\subsection{Areiões}

Os areiões constituem bermas de areia solta formadas pela ação do tráfego no centro das trilhas de roda e nas laterais da estrada, as quais impedem a saída de água (NUNES, 2003). Este defeito se origina em virtude da falta de material ligante na pista de rolamento, onde o solo, caracteristicamente arenoso, perde seus grãos que, com a passagem do tráfego, acabam se acumulando no centro e/ou nas laterais da pista de rolamento, conforme ilustra a Figura 9. Dessa forma, a presença deste tipo de defeito dificulta o escoamento de águas pluviais, contribuindo, dessa forma, para a manifestação de outros problemas ao longo da via.

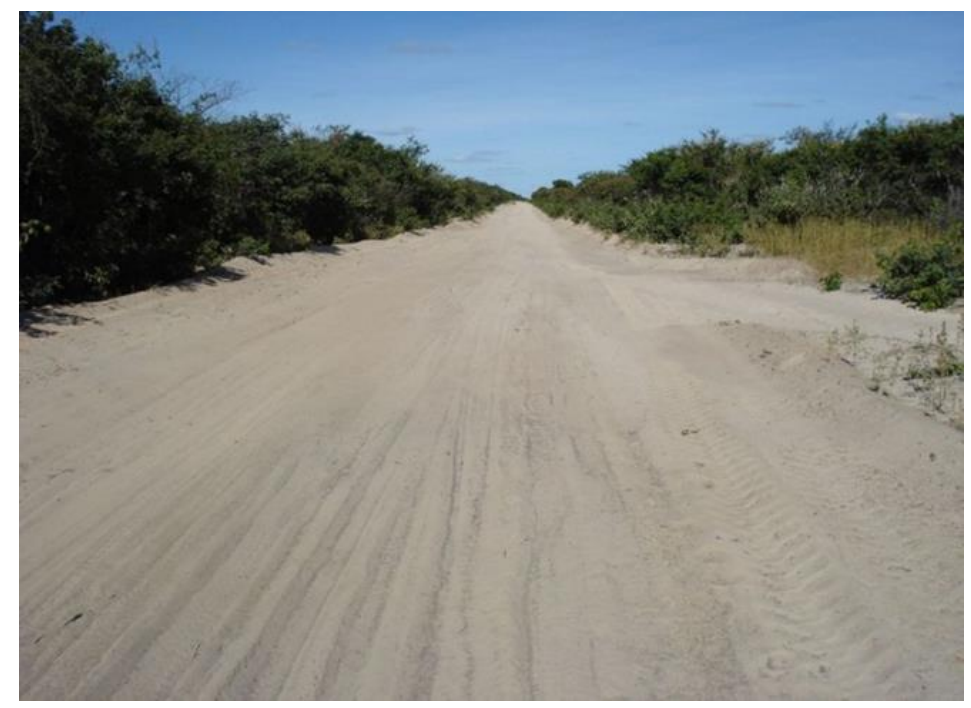

Figura 9: Estrada vicinal comprometida por areiões

Por vezes, os areiões podem ser confundidos com outros defeitos manifestados na pista de rolamento de estradas rurais, como segregação de agregados, trilhas de rodas ou facão. Entretanto, Oda (1995) afasta a dúvida ao afirmar que somente são considerados areiões quando o material solto não é importado, ao passo que há segregação de agregados quando o material granular que fica solto é importado, ou seja, pode-se considerar ocorrência de segregação de agregados caso em que o material não origina da própria configuração geológica do terreno da estrada.

Moreira (2003) mensura os areiões em função de áreas delimitadas pela largura da estrada e um comprimento linear de 4 metros. Quanto ao nível de severidade, Oda (1995) especifica:

Tabela 4 - Níveis de severidade da areiões (ODA, 1995)

\begin{tabular}{c|c}
\hline $\begin{array}{c}\text { Nível de } \\
\text { Severidade }\end{array}$ & Característica \\
\hline Baixa & bermas menores que $0,05 \mathrm{~m}$ de altura \\
\hline Média & bermas entre 0,05 e $0,15 \mathrm{~m}$ de altura \\
\hline Alta & bermas maiores que $0,15 \mathrm{~m}$ de altura \\
\hline
\end{tabular}

Para corrigir os areiões, Santos et al. (1988) aconselha a execução de uma mistura de argila com a própria areia da pista, na proporção de 1:2,5, ou confinamento com revestimento primário a fim de melhorar o solo constituinte do leito estradal. 
Verificou-se também a existência de uma outra categoria de areiões, denominada por Alves (2009) de areiões de baixada, que são caracterizados pelo acúmulo de material arenoso por meio da sedimentação da areia trazida de trechos altos, sem presença de material ligante ou compactação. Neste caso, a técnica para intervenção no problema é, basicamente, combater a erosão dos trechos altos e compactar o material já trazido.

\subsection{Erosões}

Segundo Almeida, R. (2006), erosões em estradas vicinais são defeitos causados pela ação da água em solos coesivos na ausência de dispositivos drenantes.

Santos et al. (1988) alerta para situações nas quais as erosões chegam até o nível das águas do lençol freático, o qual passa a contribuir no processo erosivo. Nestas ocasiões, as fendas são denominadas "boçorocas", cujo desenvolvimento surge em grandes dimensões e com rápida evolução.

Para este tipo de defeito, Oda (1995) peculiariza os níveis de severidade conforme Tabela 5.

Tabela 5 - Níveis de severidade de erosões (ODA, 1995)

\begin{tabular}{c|l}
\hline $\begin{array}{c}\text { Nível de } \\
\text { Severidade }\end{array}$ & \multicolumn{1}{c}{ Característica } \\
\hline Baixa & $\begin{array}{l}\text { sulcos com profundidades menores que } 20 \mathrm{~cm} \mathrm{e} \\
\text { larguras menores } 10 \mathrm{~cm} ;\end{array}$ \\
\hline Média & $\begin{array}{l}\text { sulcos com profundidades entre } 20 \mathrm{~cm} \mathrm{e} 60 \mathrm{~cm} \\
\text { largura entre } 10 \mathrm{~cm} \mathrm{e} 30 \mathrm{~cm}\end{array}$ \\
\hline Alta & $\begin{array}{l}\text { sulcos com profundidades superiores a } 60 \mathrm{~cm} \mathrm{e} \\
\text { largura maior que } 30 \mathrm{~cm} .\end{array}$ \\
\hline
\end{tabular}

Em regiões com chuvas mais intensas, o problema tende a se agravar, podendo evoluir de pequenas falhas em forma de sulcos até grandes fendas, ou ravinas, na superfície de rolamento, que impossibilitam o tráfego de veículos. A Figura 10 representa o caso onde a água escoa mediante a superfície da estrada, formando fendas que aumentam de escala proporcionalmente à medida das precipitações.

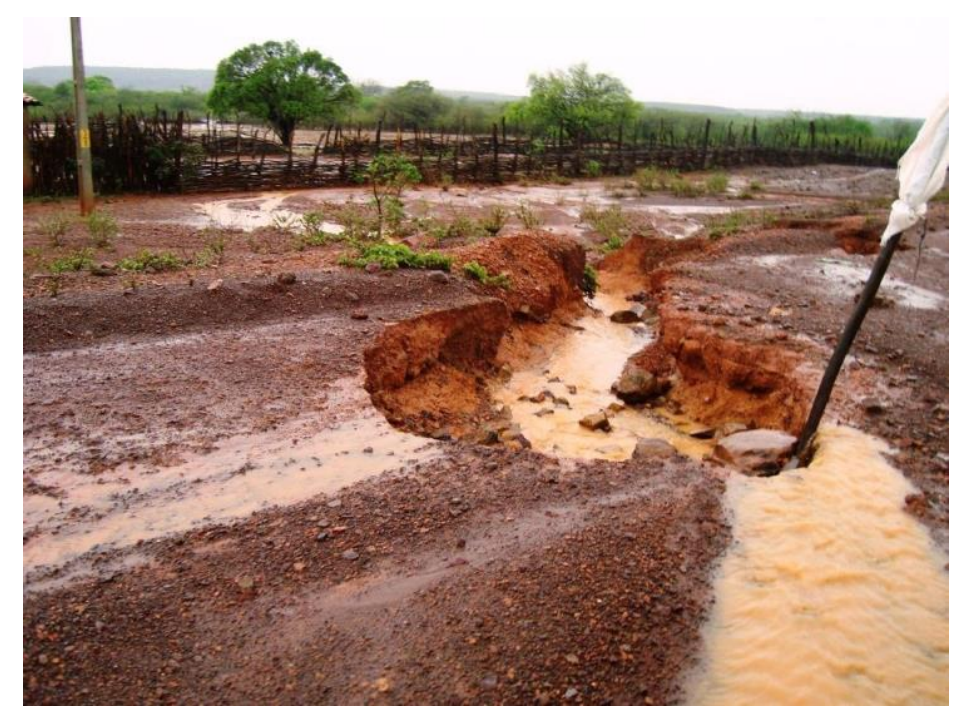

Figura 10: Erosão em um trecho de uma estrada vicinal

Tecnicamente, quando o defeito erosivo ocasionar sulcos de baixa severidade, as intervenções poderão ser executadas da mesma forma que para os buracos de mesma categoria de severidade, observando ainda que havendo repetição contínua de sulcos na pista de rolamento, deverá ser executada uma nova camada de revestimento primário.

Em contrapartida, para os casos de severidade médio-alta, Oda (1995) recomenda a execução de um sistema de drenagem eficiente que envolva: declividade transversal (de 3 a 4\%), lombadas, canaletas laterais, sarjetas, sangras, bacias de acumulação e, se necessário, plantação de grama. 


\section{CONCLUSÃO}

No estudo das características das estradas vicinais pôde-se constatar que mesmo contando com traçados já existentes, as vias não pavimentadas apresentam padrões técnicos definidos, a exemplo da seção transversal que exige vários elementos para tornar funcional a superfície da estrada, confortável e, sobretudo, conduzir as águas superficiais para os dispositivos de drenagem.

Um ponto bastante proveitoso da pesquisa foi caracterizar as diversas manifestações patológicas que prejudicam as estradas não pavimentadas. Nesse sentido, constatou-se, além das causas peculiares de cada defeito, a contribuição expressiva que a ausência de drenagem provoca às condições da via, proporcionando desde o agravamento do defeito acometido até a interrupção do tráfego na estrada.

Em relação aos custos das intervenções, resultado do levantamento, foi apontado que os custos de todos os serviços em qualquer tipo de rodovia apresentaram aumentos expressivos em função da alta do preço do petróleo nos últimos cinco anos, que reflete no preço dos materiais betuminosos e nos combustíveis.

Também é notório que os custos dos serviços em estradas vicinais aumentam significativamente quando os defeitos não são reparados. Indo além, os custos de recuperação das estradas se darão em ordem de grandeza de maior vulto quando as simples atividades de conservação não são realizadas, uma vez que foi constatado que se gasta mais com a correção do defeito do que com sua prevenção no momento em que se executam os serviços de conservação.

Frente a isso, percebe-se que os investimentos em estradas vicinais são desproporcionais à representatividade que essas vias dão à malha rodoviária do Estado do Piauí. Quanto às limitações da pesquisa, observou-se que a literatura sobre estradas não pavimentadas é consideravelmente escassa, de modo que as estradas não pavimentadas carecem de estudos técnicos mais abrangentes.

Outro aspecto notado nas buscas por informações para esta pesquisa, é que ainda não é de praxe que se elabore um projeto de engenharia completo para a execução de vias não pavimentadas. Este fato, além de ocasionar a supressão de qualquer racionalização referente aos aspectos técnicos e econômicos da obra, abre espaço para irregularidades em obras dessa natureza, em especial quando se trata de órgãos públicos, visto que os mecanismos de controle pela inexistência de projeto se tornam muito restritos.

Diante disso, vislumbra-se a necessidade de difundir técnicas adequadas para a construção e manutenção das estradas vicinais, objetivando, entre tantos aspectos, estender sua vida útil, garantir economia e racionalidade nas mais diversas intervenções, prever novas tecnologias para pavimentação de baixo custo dessas vias e, consequentemente, melhorar a aplicação de recursos públicos na contratação de serviços de implantação e manutenção de estradas vicinais. 


\section{REFERÊNCIAS}

ALMEIDA, Francisco Rogeanio Campos de. FISCALIZAÇÃo DE OBRAS RODOVIÁRIAS PELOS ÓRGÃoS DE CONTROLE EXTERNO: Um enfoque em estradas vicinais. Revista do Tribunal de Contas do Estado do Piauí, Teresina, v. 19, n. 1, p.72-81, set. 2015. Anual.

Departamento Nacional de Infraestrutura de Transportes. Ministério dos Transportes. MANUAL DE CONSERVAÇÃO RODOVIÁRIA. 2. ed. Rio de Janeiro: 2005.

Departamento Nacional de Infraestrutura de Transportes (DNIT). Ministério dos Transportes. REDE DO SNV TOTAL. Brasília: 2018.

Departamento Nacional de Infraestrutura de Transportes (DNIT). Ministério dos Transportes. TERMINOLOGIAS RODOVIÁRIAS USUALMENTE UTILIZADAS. Versão 1.1. Brasília: Diretoria de Planejamento e Pesquisa, 2007. $17 \mathrm{p}$.

CHAVES, C. R. CURSO DE CONSERVAÇÃO DE RODOVIAS. Anais do II Simpósio de Conservação de Rodovias - São Paulo, SP. 1965.

CORREIA, José Alysson Benício. UM MODELO DE ANÁLISE DE DEFEITOS EM ESTRADAS NÃO PAVIMENTADAS DE SUPORTE À CONCEPÇÃO DE UM SISTEMA DE GERÊNCIA DE

PAVIMENTOS. 2003. 101 f. Dissertação (Mestrado) - Curso de Engenharia Civil, Universidade Federal do Ceará, Fortaleza, 2003.

DNER, Departamento Nacional de Estradas de Rodagem-. MANUAL DE PROJETO GEOMÉTRICO DE ESTRADAS RURAIS. Departamento Nacional de Estradas de Rodagem, Ministério dos Transportes, 1999, 228p.

FERREIRA, Fábio Mutti. UMA APLICAÇÃo COMPARATIVA DE MÉTODOS DE AVALIAÇÃo DAS CONDIÇÕES SUPERFICIAIS DE ESTRADA NÃO-PAVIMENTADA. 2004. 248 f. Dissertação (Mestrado) Curso de Engenharia Civil, Faculdade de Engenharia Civil, Arquitetura e Urbanismo, Universidade Estadual de Campinas, Campinas, 2004.

MARIOTONI, M. (1987) RODOVIAS VICINAIS: Conceituação e Importância. Dissertação (Mestrado). Escola Politécnica. Universidade de São Paulo, São Paulo.

MOREIRA, Flávio Eduardo Batista. UM MODELO DE AVALIAÇÃO DA EVOLUÇÃO GEOMÉTRICA DAS PATOLOGIAS EM VIAS NÃO PAVIMENTADAS: Aplicação ao caso do Município de Aquiraz. 2003. 197 f. Dissertação (Mestrado) - Curso de Engenharia Civil, Universidade Federal do Ceará, Fortaleza, 2003.

ODA, Sandra. CARACTERIZAÇÃo DE UMA REDE MUNICIPAL DE ESTRADAS NÃO

PAVIMENTADAS. 1995. 186 f. Dissertação (Mestrado) - Curso de Engenharia Civil, Escola de Engenharia de São Carlos, Universidade de São Carlos, São Carlos, 1995.

OLIVEIRA, Mário José Garrido de. HIERARQUIZAÇÃo PARA ORIENTAR A MANUTENÇÃo DE RODOVIAS NÃO PAVIMENTADAS. 2005. 124 f. Tese (Doutorado) - Curso de Engenharia Civil, Escola de Engenharia de São Carlos, Universidade de São Carlos, São Carlos, 2005.

Departamento de Estradas e Rodagem. Secretaria dos Transportes. REDE RODOVIÁRIA ESTADUAL E MUNICIPAL: Extensões totais em 11/2013. Teresina: Piauí, 2013

SANTOS, A. R.; PASTORE, E. L.; AUGUSTO JR, F.; CUNHA, M. A. ESTRADAS VICINAIS DE TERRA: Manual Técnico para Conservação e Recuperação. $2^{a}$. ed. São Paulo: Instituto de Pesquisas Tecnológicas - IPT, $1988,125 \mathrm{p}$.

SILVA, Taciano Oliveira da. ESTUdO DE ESTRADAS NÃo PAVIMENTADAS DA MALHA VIÁRIA DO MUNICÍPIO DE VIÇOSA-MG. 2009. 130 f. Tese (Doutorado) - Curso de Engenharia Civil, Universidade Federal de Viçosa, Viçosa-MG, 2009. 